\title{
Card sorting: adaptação da técnica para aplicação ao design de sistemas de informação não digitais
}

\author{
Card sorting: adaptation of the technique for application \\ to non-digital information system design
}

Stephania Padovani, Murilo Amgarten Ribeiro

card sorting, design centrado no usuário, adaptação card sorting, user-centred design, adaptation
Este estudo teve como objetivo adaptar a técnica de card sorting para aplicação a sistemas de informação não digitais. Usualmente apropriado ao desenvolvimento participativo de arquitetura da informação de sistemas digitais, o card sorting passou por uma adaptação de conceitos, métricas e procedimentos para então ser aplicada a três sistemas diferentes: embalagem alimentícia, manual de instruções de eletrodoméstico e mapa turístico impresso. Os resultados da aplicação com 45 usuários revelaram que os participantes compreenderam os objetivos da técnica adaptada e geraram dados diretamente aplicáveis ao design dos sistemas escolhidos. Como desdobramentos, vislumbram-se a ampliação do escopo do card sorting, envolvendo também a ordenação e hierarquização (e não apenas o agrupamento) e a aplicação por pesquisadores não envolvidos no processo de adaptação da técnica.

This study aimed to adapt the card sorting technique so as to apply it to non-digital information systems. Usually appropriate for participatory development of digital system information architecture, the technique went through a conceptual, metrical end procedural adaptation before it could be applied to three different information systems: food package, home appliance instruction manual and printed tourist map. The results of its application with 45 users revealed that participants fully understood the aims of the adapted technique and generated data that is directly applicable to de design of the systems at hand. Future work includes broadening the scope of card sorting to comprise ordering and hierarchy (not only grouping) and its application by researchers that were not involved in its adaptation process.

\section{Introdução}

Envolver ativamente stakeholders durante o processo de desenvolvimento de sistemas de informação é um dos aspectos que caracteriza e diferencia a abordagem de Design-Centrado no Usuário (DCU). Nesse sentido, a ideia de que um sistema de informação possa ser desenvolvido exclusivamente por colaboração interna do time de 
projeto (associada a feedback do cliente) e, apenas após a geração de um protótipo de alta fidelidade, realize-se uma consulta ao público alvo é fortemente rechaçada por diversos autores da área de DCU.

Cato (2001), por exemplo, argumenta que usuários são parte essencial do estágio de descoberta. $\mathrm{O}$ autor defende que os projetistas precisam dos usuários desde o ponto em que entendem quem eles são, pois ao envolver usuários apenas no final do projeto, provavelmente 80 a $90 \%$ do trabalho já estará concluído e só então se descobrirá que há algo errado. Cybis et al. (2007) compartilham essa opinião ao afirmarem que quando os usuários são envolvidos desde cedo no desenvolvimento, reduz-se o risco de falhas conceituais no projeto. Os autores defendem que a cada ciclo de teste e refinamento, o sistema responderá cada vez melhor às expectativas e necessidades dos usuários.

Diante dessa perspectiva, com vistas a envolver usuários em diferentes momentos do processo de design, encontram-se na literatura uma série de métodos e técnicas já direcionados para fases específicas deste processo (e.g., análise de usuário-tarefa-contexto, síntese de requisitos, concepção, ideação, detalhamento, validação). Maguire (2001), por exemplo, apresenta um conjunto de métodos/ técnicas alocados nos 5 grandes sub-processos do ciclo de Design Centrado no Humano (ISO 9241-210): planejamento do processo, entendimento do contexto de uso, especificação de requisitos, produção de soluções de design e protótipos e avaliação com base nos requisitos. Cybis et al. (2007) também propõem e descrevem os procedimentos de aplicação de métodos e técnicas de ergonomia e usabilidade, distribuídos nas três grandes fases do ciclo de engenharia de usabilidade: análise, síntese e avaliação. Mais recentemente, levantamento similar foi conduzido por Santa Rosa \& Moraes (2012), mas dessa vez com ênfase na arquitetura da informação em sistemas digitais, com destaque para as técnicas de grupo de foco, card sorting, avaliação heurística e questionários de satisfação. Ainda à semelhança, Stickdorn \& Schneider (2011) compilaram e organizaram uma série de métodos/técnicas para envolvimento de stakeholders durante as três fases principais do design de serviços, delimitadas pelos autores como "explorar", "criar e refletir" e "implementar".

Entretanto, em contraste com esse panorama de diversidade metodológica, uma revisão da literatura nos mostra que a grande maioria dos estudos aplicando esses métodos e técnicas se direcionam para os sistemas de informação digitais. Padovani et al. (2012), por exemplo, verificaram que, no período de 2000 a 2011, em levantamento realizado em 5 congressos e 2 revistas nacionais da área de Design, para um universo de 15 métodos originalmente concebidos para sistemas digitais, mas passíveis de adaptação e aplicação a sistemas não-digitais, apenas a avaliação heurística e o teste de usabilidade foram efetivamente utilizados. Ainda assim, apenas 6 publicações (no período de pesquisa considerado) se apropriaram desses métodos, incluindo-os no design ou avaliação de sistemas de informação em suporte impresso. 
Diante do exposto, a presente pesquisa busca contribuir para uma lacuna na literatura de design de sistemas de informação não digitais, no que se refere a métodos e técnicas de inclusão do usuário nas fases intermediárias do processo de design: síntese de requisitos, estruturação da informação, concepção e ideação. Essas fases foram selecionadas em face ao uso corrente (reportado na literatura) de métodos e técnicas tradicionais nas fases iniciais do processo de design, como por exemplo, questionários, entrevistas e grupos de foco, ou ainda nas fases finais de avaliação, como os já mencionados testes de usabilidade e avaliações heurísticas. O presente estudo caracteriza-se, então, como um recorte de projeto de pesquisa maior, ao enfocar especificamente a adaptação da técnica de card sorting, criada originalmente para construção participativa da arquitetura da informação de sistemas digitais.

Inicialmente, apresenta-se uma visão geral da técnica, abordando seus objetivos e procedimentos de aplicação e análise. Em seguida, explica-se o processo de adaptação do card sorting para aplicação a suporte impresso. Por fim, apresentam-se os procedimentos e discutem-se os resultados do card sorting para embalagem, manual de instruções e mapa turístico.

\section{Card sorting - visão geral da técnica}

A técnica de card sorting (também traduzida como arranjo de cartas) consiste em escrever informações ou funções em cartões e solicitar que participantes (individualmente) as agrupem da maneira como consideram que faça sentido semanticamente. Em seguida, o pesquisador analisa as composições geradas, buscando similaridades para unificá-las em uma estrutura única.

Nielsen (1993) explica que o principal objetivo do card sorting é compreender a representação mental do conhecimento dos usuários e como estes usuários modelam determinado domínio. Kuniavsky (2003) propõe definição similar, ao apresentar o card sorting como uma técnica que utilizada para descobrir como as pessoas organizam informação e como categorizam e relacionam conceitos. Cybis et al. (2007), enxergam esse objetivo já aplicado ao design de sistemas, afirmando que o card sorting é empregado para descobrir a representação ou modelo mental que os usuários elaboram sobre o conjunto de itens de informação pretendidos para um programa ou aplicação. Santa Rosa \& Moraes (2012) acrescentam a estes objetivos aspectos mais operacionais e observáveis, listando os seguintes propósitos de aplicação do card sorting:

- identificar a terminologia que usuários compreendem mais facilmente;

- identificar os itens difíceis de classificar;

- identificar informações que possam pertencer a mais de um grupo; 
- perceber como diferentes públicos-alvo categorizam o conteúdo;

- perceber como cada perfil de usuário pode acessar determinado conteúdo.

Por fim, Hudson (2013) sintetiza esses objetivos em três grandes categorias, para as quais os resultados do card sorting podem contribuir:

- terminologia (como as pessoas nomeiam as coisas);

- relações (de proximidade ou similaridade);

- categorias (grupos e seus nomes).

\subsection{Condução do card sorting}

O processo de condução do card sorting envolve, basicamente, três estágios: planejamento, arranjo dos cartões e eliciação.

Cybis et al. (2007) explicam que o estágio de planejamento tem início com a identificação dos itens de informação que devem ser organizados pelos participantes. Cada item é escrito em um cartão de papel. Caso existam categorias já definidas para enquadramento das informações (card sorting fechado ou top-down), deve-se preparar cartões com cores diferentes contendo os nomes das categorias ou recipientes (rotulados ou não) para colocar os cartões. No card sorting aberto (ou bottom-up), todos os cartões serão da mesma cor e não haverá uma quantidade definida de categorias a preencher com informações. Neste caso, é necessário deixar cartões em branco (podem ser de cor diferente) para que os participantes nomeiem as categorias geradas, ou mesmo cartões de mesma cor para que os usuários acrescentem informações à base de dados.

Também faz parte do planejamento a seleção dos participantes. Estes devem representar o público alvo que utilizará o sistema, incluindo desde usuários novatos até usuários especialistas. A quantidade ideal de participantes, com melhor relação de custobenefício, segundo Tullis \& Albert (2008), é de 15 indivíduos, o que gera uma taxa de $90 \%$ de equivalência com amostras maiores, ou seja, no máximo $10 \%$ dos resultados será diferente, caso opte-se por aumentar a quantidade de participantes. Com 20 participantes, por exemplo, chega-se a $92 \%$ e com 30 indivíduos a $96 \%$.

O estágio de arranjo, segundo Cybis et al. (2007) inicia-se com o pesquisador (facilitador) embaralhando os cartões, para que nenhum participante receba os cartões na mesma ordem. O participante é então orientado a distribuir os cartões em pilhas por similaridade semântica, com base em seus próprios critérios. No caso do card sorting fechado, o participante deve criar uma quantidade específica de pilhas previamente rotuladas ou não. Para o card sorting aberto, o participante tem liberdade em criar quantas pilhas quiser, deixar cartões de fora das pilhas (se não souber onde enquadrá-las) e 
acrescentar cartões (criando seus próprios rótulos), se achar que algo está faltando. Caso algum rótulo não esteja claro, pode-se ainda permitir ao usuário que altere a nomenclatura no próprio cartão (MAURER \& WARFEL, 2004). Wood \& Wood (2008) recomendam que o facilitador seja explícito neste fase sobre o propósito do agrupamento e onde os resultados serão aplicados (e.g., agrupe os itens da forma como espera / gostaria de encontrá-los em nosso portal corporativo).

Após a criação das pilhas, o facilitador pode solicitar ao participante que ordene os cartões dentro de cada categoria e/ou relacione as categorias entre si, criando uma estrutura única. Além disso, o participante pode desenhar linhas e setas para explicitar as relações entre os cartões. A estrutura resultante deve ser registrada pelo pesquisador (e.g., desenho, lista, foto), antes que os cartões sejam novamente embaralhados para a próxima sessão de arranjo.

O estágio de eliciação, não obrigatório na aplicação do card sorting, consiste em solicitar a cada participante que explique porque agrupou os cartões da maneira como o fez, ou seja, qual foi sua lógica de organização. Esse depoimento deve ser gravado, para posterior transcrição. Essa informação auxiliará o pesquisador no caso de dúvidas quando necessitar unificar as estruturas produzidas pelos participantes.

\subsection{Análise de resultados do card sorting}

A análise dos resultados para o card sorting pode ocorrer de maneira informal ou formal. Conforme Santa Rosa \& Moraes (2012), o modo informal pode ser aplicado quando de tem um grupo relativamente pequeno de cartões e torna-se fácil observar os agrupamentos gerados e reconhecer padrões por meio de agrupamento e rotulagens semelhantes. O tratamento realizado deste modo não trará uma resposta definitiva para a estrutura do sistema, mas sim uma indicação, a qual necessitará de avaliação posterior.

Para a análise formal de card sorting fechado, de acordo com Tullis \& Albert (2008), o objetivo é descobrir se os participantes enquadraram os cartões nas categorias "corretas" (previstas pelos pesquisadores). Para tanto, pode-se calcular a porcentagem de usuários que enquadrou o cartão em cada categoria, assim como o valor máximo de enquadramento correto, do segundo lugar em enquadramento e a diferença entre ambos (vide tabela 01).

Se tomarmos a primeira linha da tabela 01, por exemplo, o cartão 01 deveria ter sido enquadrado na categoria B. Temos que $78 \%$ dos participantes o enquadraram na categoria prevista, mas $17 \%$ o enquadraram "incorretamente" na categoria A ( $2^{\circ}$ lugar). Portanto, a diferença é de $61 \%$. Procedendo desta mesma forma para todos os cartões, obtemos as médias dos valores máximos de enquadramento correto e das diferenças, o que nos permite avaliar o quanto a estrutura proposta pelos desenvolvedores do sistema correspondeu às expectativas dos usuários. 
Tabela 1 Tabulação de dados para análise de card sorting fechado (fonte: Tullis \& Albert, 2008)

\begin{tabular}{|c|c|c|c|c|c|c|}
\hline cartão & categoria A & categoria B & categoria C & $\begin{array}{l}\text { máx. enq. } \\
\text { correto }\end{array}$ & 2 - lugar & diferença \\
\hline 01 & $17 \%$ & $78 \%$ & $5 \%$ & $78 \%$ & $17 \%$ & $61 \%$ \\
\hline 02 & $15 \%$ & $77 \%$ & $8 \%$ & $77 \%$ & $15 \%$ & $62 \%$ \\
\hline 03 & $20 \%$ & $79 \%$ & $1 \%$ & $79 \%$ & $20 \%$ & $60 \%$ \\
\hline 04 & $48 \%$ & $40 \%$ & $12 \%$ & $48 \%$ & $40 \%$ & $8 \%$ \\
\hline 05 & $11 \%$ & $8 \%$ & $81 \%$ & $81 \%$ & $11 \%$ & $70 \%$ \\
\hline 06 & $1 \%$ & $3 \%$ & $96 \%$ & $96 \%$ & $3 \%$ & $93 \%$ \\
\hline 07 & $46 \%$ & $16 \%$ & $37 \%$ & $46 \%$ & $37 \%$ & $8 \%$ \\
\hline 08 & $57 \%$ & $38 \%$ & $5 \%$ & $57 \%$ & $38 \%$ & $18 \%$ \\
\hline 09 & $20 \%$ & $75 \%$ & $5 \%$ & $75 \%$ & $20 \%$ & $55 \%$ \\
\hline \multirow[t]{2}{*}{10} & $4 \%$ & $5 \%$ & $92 \%$ & $92 \%$ & $5 \%$ & $87 \%$ \\
\hline & & & médias & $73 \%$ & & $52 \%$ \\
\hline
\end{tabular}

A análise formal de card sorting aberto, por sua vez, envolve procedimentos mais complexos. Inicialmente, Tullis \& Albert (2008) recomendam que seja construída uma matriz de distância percebida entre todos os pares de cartões do estudo. Se o participante enquadrar um par de cartões em um mesmo grupo, a interseção na matriz recebe o valor o (zero). Caso o par de cartões seja enquadrado em grupos diferentes, a interseção recebe o valor 1 (um). A soma dos enquadramentos de todos os participantes gera a matriz de distâncias percebidas (vide tabela 02 ).

Na tabela 2, por exemplo, pêssegos e laranjas foram as frutas consideradas mais similares pelos participantes, visto que apresentam a menor distância (2). Já tomates e bananas foram consideradas as frutas mais diferentes pelos participantes, por apresentarem a maior distância (20), ou seja, todos os participantes os enquadraram em grupos diferentes.

Tabela 2 Matriz de distância percebida para card sorting com 20 participantes (fonte: Tullis \& Albert, 2008)

\begin{tabular}{|c|c|c|c|c|c|c|c|c|c|c|}
\hline & maçã & laranja & morango & banana & pêssego & ameixa & tomate & pera & uva & cereja \\
\hline maçã & --- & 5 & 11 & 16 & 4 & 10 & 12 & 8 & 11 & 10 \\
\hline laranja & & --- & 17 & 14 & 2 & 12 & 15 & 11 & 12 & 14 \\
\hline morango & & & --- & 17 & 16 & 8 & 18 & 15 & 4 & 8 \\
\hline banana & & & & --- & 17 & 15 & 20 & 11 & 14 & 16 \\
\hline pêssego & & & & & --- & 9 & 11 & 6 & 15 & 13 \\
\hline ameixa & & & & & & --- & 12 & 10 & 9 & 7 \\
\hline tomate & & & & & & & --- & 16 & 18 & 14 \\
\hline pera & & & & & & & & --- & 12 & 14 \\
\hline uva & & & & & & & & & -- & 3 \\
\hline cereja & & & & & & & & & & --- \\
\hline
\end{tabular}


Outra forma de tratar resultados de card sorting aberto é a partir de análise hierárquica de cluster. Neste caso, produz-se uma árvore (também intitulada dendograma por alguns autores) em que os cartões tidos como mais similares pelos participantes são posicionados em ramos próximos. Cartões cujos ramos se juntam primeiro são, portanto, mais similares que aqueles que se juntam posteriormente. Na figura 01, visualiza-se, em forma de árvore, o mesmo conjunto de dados apresentados na tabela 2.

De posse do dendograma, para estabelecer a quantidade de grupos a utilizar e quais itens devem ser enquadrados em cada grupo, estabelece-se uma linha de corte (representada em vermelho na figura 01). O posicionamento desta linha de corte deve ser escolhido de acordo com a média de grupos criada pelos participantes. Por exemplo, na figura 1, como a média de grupos criados pelos participantes foi 4 , escolheu-se uma posição para a linha de corte em que ela intercepta exatamente 4 ramos. Formaram-se, então, 4 grupos contendo os itens agrupados dentro de cada ramo: (a) banana; (b) tomate; (c) ameixa, cereja, uva e morango; (d) pêra, pêssego, laranja e maçã.

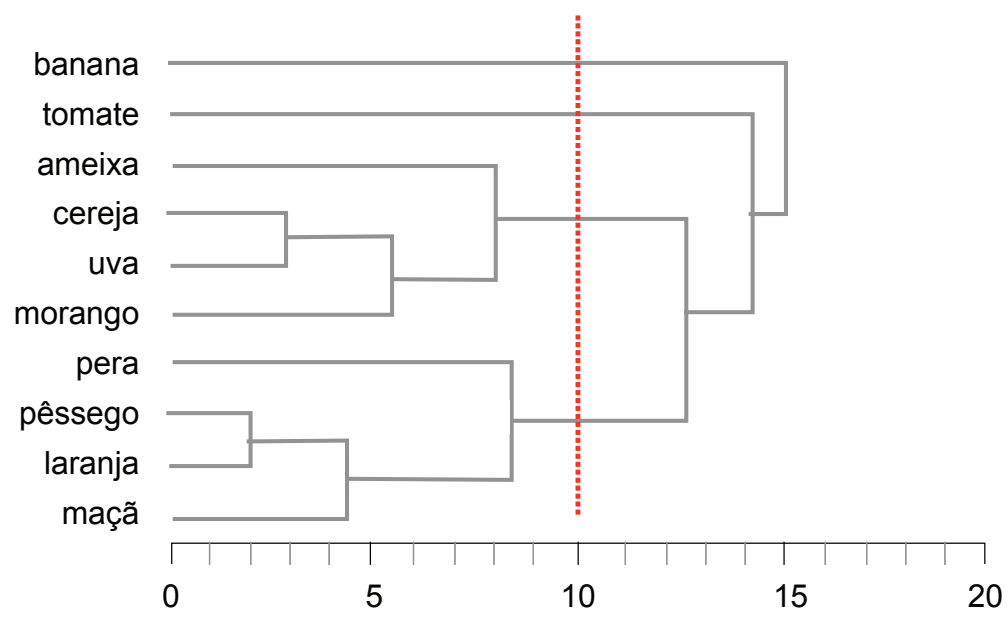

Figura 1 Dendograma (árvore) representando os resultados mostrados na tabela 02.

\section{Processo de adaptação do card sorting}

A técnica de card sorting foi adaptada em um processo constituído de três fases: mapeamento das necessidades de adaptação, adaptação conceitual e adaptação de métricas e procedimentos.

O mapeamento das necessidades de adaptação aparece representado de forma sintética na figura 2. Listaram-se os conceitos, métricas e procedimentos envolvidos na aplicação do card sorting, conforme mencionados na literatura especializada. De posse do diagrama, três pesquisadores com atuação tanto na área de interação humano-computador quanto design da informação em suporte impresso selecionaram os itens que consideraram necessitar de adaptação. 


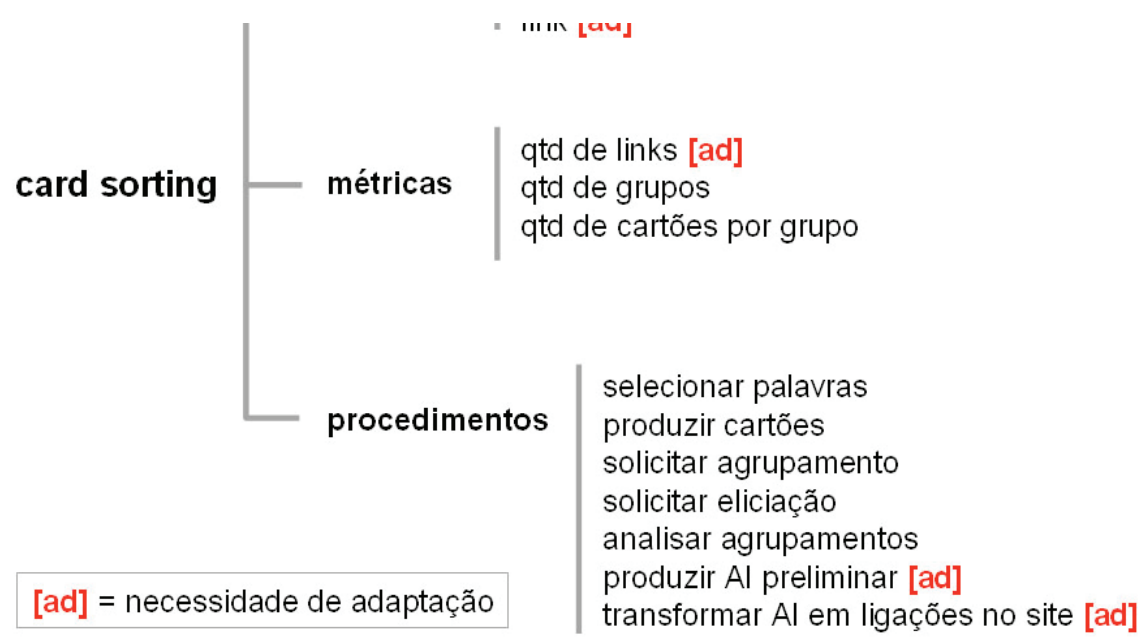

Figura 2 Necessidades de adaptação para a técnica de card sorting.

Para cada um dos itens com necessidade de adaptação, buscaram-se definições na literatura e/ou explicações detalhadas das métricas e procedimentos. Os pesquisadores analisaram, em conjunto, as informações coletadas na literatura e propuseram, então, novas definições, métricas e procedimentos.

No que se refere aos conceitos adaptados, obtiveram-se os seguintes:

- arquitetura da informação: organização e rotulagem de dados a serem incluídos em um sistema de informação (os itens navegação e ferramenta de busca foram retirados);

- área de informação (o termo interação foi substituído): grupo de nós de informação relacionados entre si e que se diferenciam de outros grupos;

- nó de informação: unidade autônoma de conteúdo que não deve ser dividida em partes menores e cujo conjunto organizado compõe a arquitetura da informação;

- link: item que remete a outro nó de informação ou a elemento específico em outro nó de informação, usualmente próximo aos termos "vide", “consulte também”, "refira-se a”, "encontra-se em".

Se tomarmos, por exemplo, uma embalagem, a arquitetura da informação corresponderia ao conjunto de informações organizadas nas diferentes faces da embalagem. Cada face, por sua vez, corresponderia a uma área de informação, nós de informação seriam grupos de informações que se organizam para formar cada 
face. Exemplos comuns de nós seriam marca+nome do produto (e.g., lasanha sadia), informações nutricionais, ingredientes, modo de preparo. Por fim, links seriam informações que remetem a outras partes da embalagem, como, por exemplo, os dizeres "para validade e lote do produto, consulte a face inferior da embalagem", ou ainda asteriscos em tabelas que remetem a informações em legendas.

Com relação às métricas, optou-se por restringir-se à quantidade de grupos e quantidade de cartões por grupo, excluindo-se, portanto a quantidade de links, visto que não há necessidade de criar ferramentas de navegação nos sistemas de informação em suporte impresso. Outro aspecto importante relacionado às métricas, é a possibilidade de repetição de nó de informação em várias áreas de informação, o que não ocorreria em um sistema de informação digital. Por exemplo, em uma embalagem, o nó marca+nome do produto aparecerá em praticamente todas as faces.

Por fim, com relação aos procedimentos de aplicação da técnica, o planejamento e a condução do card sorting se mantiveram, com acréscimo de alguns materiais tangíveis, como, por exemplo, embalagens planificadas para facilitar o enquadramento dos itens e facilitar a visualização do tamanho das áreas de informação disponíveis. A produção da arquitetura de informação preliminar foi mantida, mas com formas de representação alternativas à convencional árvore utilizada para os sistemas digitais. Sugere-se, por exemplo, o uso de planificações com nós de informação (para embalagens - vide figura 3), ou de planos interligados (para representar partes de manual de instruções ou mesmo camadas de informação em um mapa).

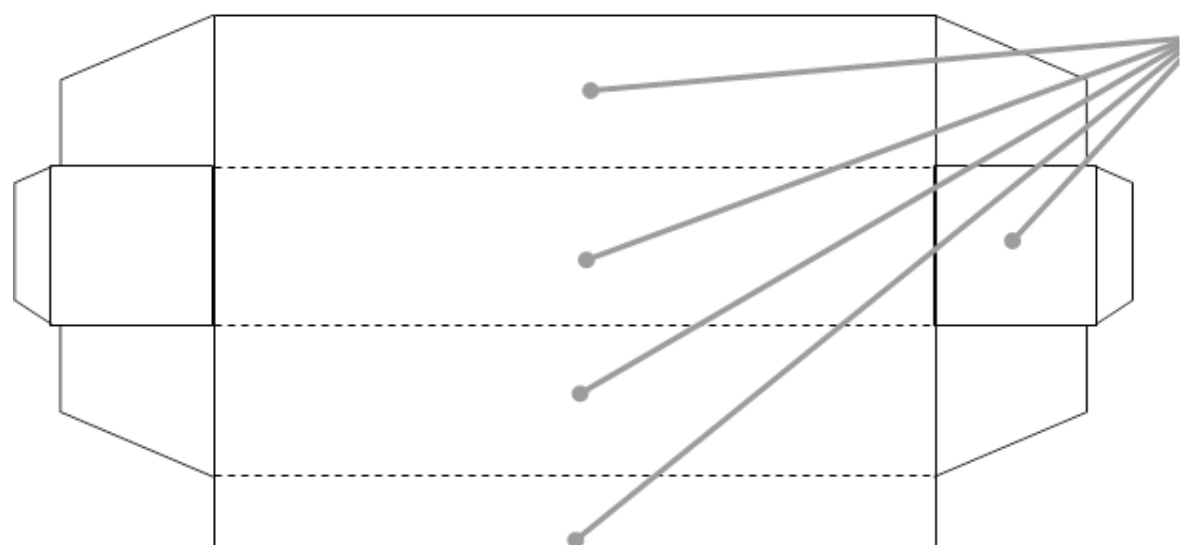

marca + tipo de pasta benefícios esperados recomendações de uso quantidade ingredientes instruções de uso advertências informações fabricante código de barras

Figura 3 Listagem de nós de informação e alocação de um deles nas faces de uma embalagem 


\section{Aplicação do card sorting adaptado}

Para a aplicação da versão adaptada da técnica de card sorting selecionamos três sistemas de informação em suporte impresso de tipos diferentes:

- embalagem alimentícia: representante de card sorting do tipo fechado (quantidade fixa de grupos, cada um correspondendo a uma face da embalagem), com arquitetura final sem ordem fixa (a leitura das faces da embalagem não tem uma ordem fixa);

- manual de instruções de eletrodoméstico: representante de card sorting do tipo aberto (sugestão de grupos, com possibilidade de acréscimo pelo usuário), com arquitetura final com ordem fixa (os capítulos e informações correspondentes possuem uma sequência no manual);

- mapa turístico de cidade: representante de card sorting do tipo aberto (com possibilidade de acréscimo de itens pelo usuário, mas com grupos fixos), com arquitetura final sem ordem fixa (cada usuário lerá os itens de um mapa conforme sua situação).

Participaram do card sorting 45 indivíduos distribuídos em 3 grupos de 15. Cada participante agrupou os cartões para apenas um tipo de sistema de informação.

\subsection{Card sorting para embalagem alimentícia}

O objetivo da aplicação do card sorting em embalagem foi envolver os usuários na decisão de quais informações incluir em que faces da embalagem. A técnica poderia ser usada tanto para criar uma nova embalagem, quanto para verificar se uma embalagem já existente estaria organizada de acordo com a expectativa dos usuários.

Para tal, inicialmente, selecionaram-se na embalagem original as informações para constar nos cartões (post-its) e produziu-se uma planificação no tamanho real da embalagem de lasanha. O uso de uma planificação para agrupamento dos cartões foi adotado, principalmente, devido ao caráter tridimensional das embalagens. Utilizando a planificação, torna-se mais claro para o participante, como esta se apresentaria fechada e posicionada em uma gôndola ou freezer, por exemplo. Mais ainda, a noção exata do tamanho relativo entre faces também visa facilitar a alocação de informações nas mesmas.

Os rótulos dos post-its, informações extraídas da embalagem original de lasanha foram: marca, sabor, peso, porção (serve $\mathrm{X}$ pessoas), outros sabores, modo de preparo, instrução sobre temperatura, informação nutricional, conservação do produto, fabricação e validade. A planificação foi apresentada em papel branco, 
sem imagens ou quaisquer outros elementos gráficos que passassem sugestões para enquadramento de informações. Sinalizaram-se as partes da frente e de trás da embalagem e as outras faces foram numeradas de 1 a 4 .

De posse do material, cada participante, em sessão presencial individual, posicionou os cartões (post-its) nas 6 faces da embalagem (figura 4) livremente e com a possibilidade de re-posicioná-las, até que chegasse ao arranjo que considerasse finalizado. Explicou-se, ainda, aos participantes, que era possível "clonar" os cartões se ele considerasse que uma mesma informação deveria aparecer em mais de uma face da embalagem. O participante deveria, também, explicar como estava organizando as informações durante o arranjo de cartões ou após a conclusão da sessão, ficando a seu critério. Toda a sessão foi gravada em áudio para posterior transcrição.

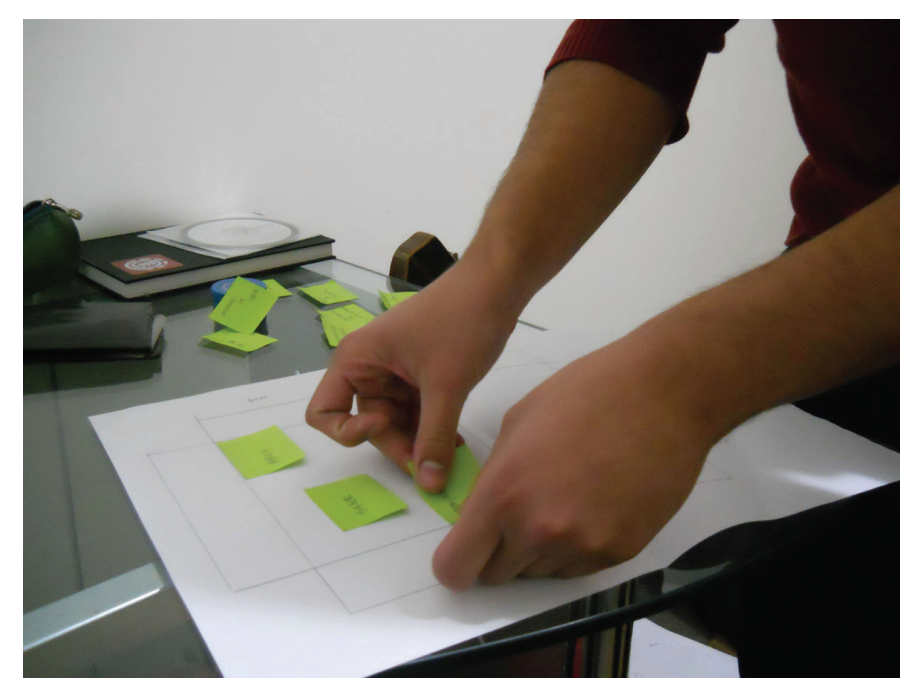

Figura 4 Participante organizando os post-its sobre a planificação da embalagem

Os resultados do card sorting para embalagem revelaram que $60 \%$ das informações foram enquadradas de forma praticamente unânime pelos participantes. Foi o caso de "marca" e "sabor", inseridas na face frontal por $100 \%$ dos participantes, assim como "outros sabores" e "modo de preparo", posicionadas por $93 \%$ dos participantes na face de trás da embalagem. Peso e informação nutricional também foram alocadas pela maioria dos participantes ( $80 \%$ ) na face frontal e traseira, respectivamente. Por fim, os outros quatro itens (porção, instrução sobre temperatura, conservação e fabricação e validade), tiveram enquadramento extremamente diversificado, sem que fosse possível verificar alguma tendência. 
Tabela 3 Tabulação dos resultados do card sorting para embalagem de lasanha

\begin{tabular}{|c|c|c|c|c|c|c|}
\hline \multirow[b]{3}{*}{ cartões } & & & & & & \\
\hline & \multicolumn{6}{|c|}{ \% de inserção nas faces da embalagem } \\
\hline & frente & trás & face 01 & face 02 & face 03 & face 04 \\
\hline marca & 100 & & & & & \\
\hline sabor & 100 & & & & & \\
\hline peso & 80 & & 06 & 13 & & \\
\hline porção & 46 & 26 & 06 & 13 & 13 & \\
\hline outros sabores & & 93 & 06 & & & \\
\hline modo de preparo & & 93 & 06 & & & \\
\hline instrução sobre temperatura & 13 & 54 & 06 & 13 & 13 & \\
\hline informação nutricional & & 80 & & 13 & 06 & \\
\hline conservação & & 53 & 6 & & 34 & 06 \\
\hline fabricação e validade & 13 & 13 & 13 & & 20 & 40 \\
\hline
\end{tabular}

Com a observação dos participantes durante as sessões, aliada aos comentários proferidos, foi-nos possível verificar que estes se mostraram pouco à vontade com o exercício de arranjo de post-its, considerando-o complexo e pouco estimulante. Entretanto, ao analisar os resultados, percebemos que os participantes compreenderam a dinâmica, pois os resultados são bastante uniformes.

Poucos, ainda, foram os participantes que decidiram comentar sobre os critérios utilizados para organizar os post-its na embalagem. Nos comentários, ficou claro que o principal critério para enquadramento das informações foi sua importância, ou seja, na face frontal deveriam ficar as informações mais importantes para auxiliar o consumidor no momento da compra, enquanto na parte de trás, informações de preparo, uso e dicas para a próxima compra.

Outro aspecto interessante que apareceu nos comentários foi a tentativa de alguns participantes em lembrar como as informações apareciam em embalagens que já havia comprado, em que houve maior facilidade em lembrar das informações que ficavam nas faces maiores da embalagem (frente e trás) e maior dificuldade em lembrar das informações nas faces laterais.

\subsection{Card sorting para manual de instruções de eletrodoméstico}

O objetivo de aplicação do card sorting para manual de instruções foi envolver os usuários na decisão sobre como organizar as informações dentro dos principais capítulos do manual. Uma versão mais complexa da técnica poderia também envolver a ordenação dos capítulos resultantes, após o enquadramento das informações. Também poderia ser aplicado o card sorting para verificar se as informações em um manual já existente estavam organizadas de acordo com as expectativas dos usuários. 
Para tal, inicialmente, selecionaram-se no manual de instruções de micro-ondas as informações para constar nos cartões. As informações foram, então, inseridas na ferramenta de card sorting digital websort (figura 5). Dentro do websort, criaram-se também as categorias de enquadramento, nas quais os cartões deveriam ser inseridos. Para este card sorting, diferentemente do caso da embalagem, não se sentiu a necessidade de produzir material concreto de apoio.

As sete categorias geradas para o card sorting (correspondendo às partes principais do manual) foram: instruções de segurança; partes do micro; como usar; limpeza e manutenção; guia de soluções; informações técnicas, acessórios. Já os itens a serem distribuídos nas categorias foram: posicionamento do forno; circulação de ar; circuitos; disjuntores; tensão da tomada; painel de controle; como o forno funciona; ajustes de relógio; ajustes de tempo de cozimento e potência; cozimento 30s; interrompendo o cozimento; aviso sonoro; abrindo a porta do forno; funções de segurança; utilizando a trava de segurança; alterando intensidade luminosa; dúvidas mais comuns.

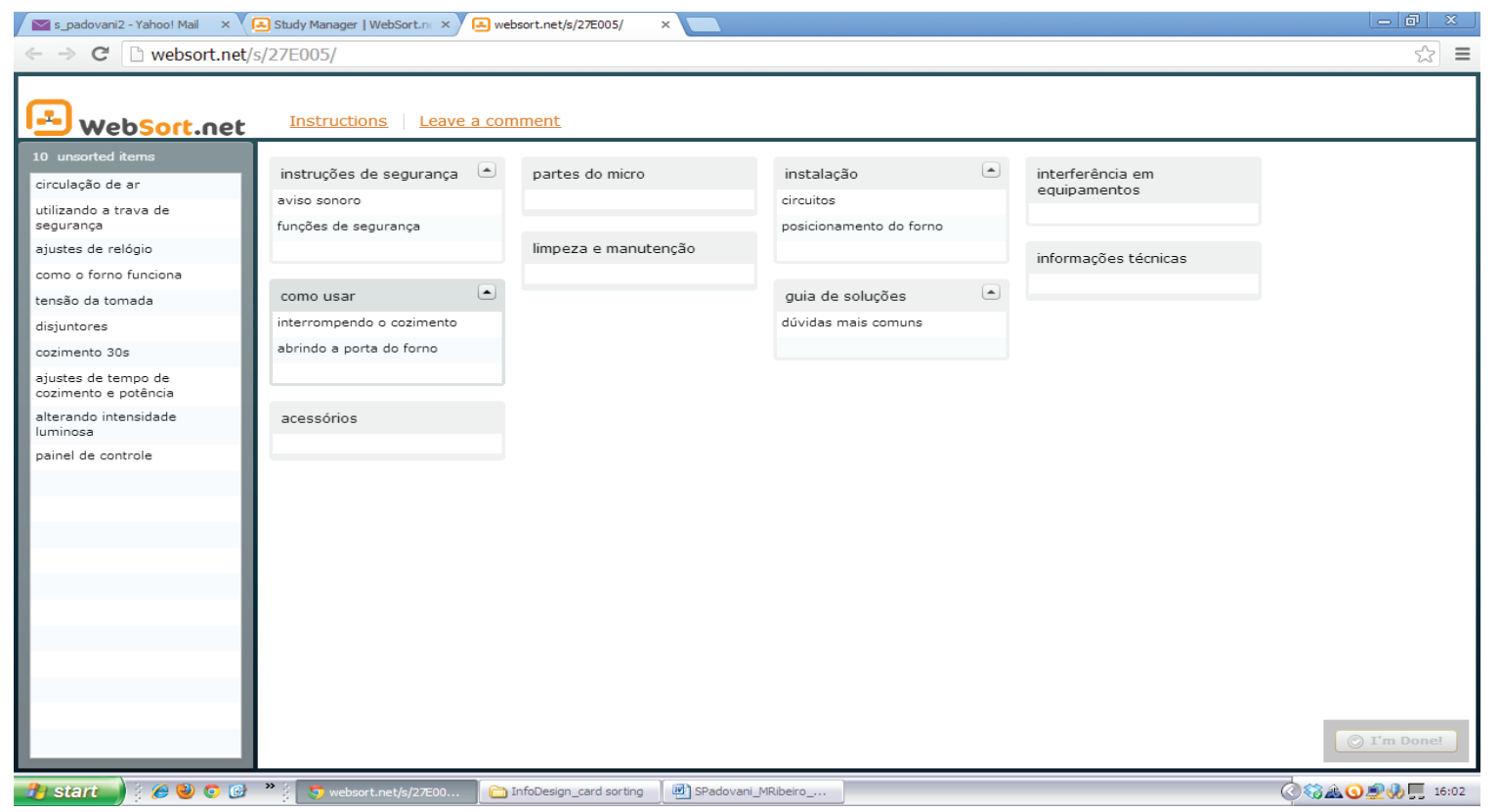

Figura 5 Tela do websort com distribuição de informações em andamento por um dos participantes

Cada participante, então, individualmente, acessou o site do websort e distribuiu as informações dentro das categorias geradas. Neste caso, não era permitido "clonar" cartões, nem acrescentar informações novas ou categorias, sendo o card sorting caracterizado como fechado. Após a distribuição dos cartões, os participantes poderiam comentar sobre seus critérios de agrupamento, deixando uma mensagem para o pesquisador na própria página do websort ou enviando-a para os endereços de e-mail dos pesquisadores. 
Os resultados da aplicação do card sorting para o manual de microondas revelaram que para apenas quatro das dezessete informações houve certa unanimidade de distribuição pelos participantes (vide tabela 4). Foi o caso, por exemplo, de "como o forno funciona", "ajustes de tempo de cozimento e potência", "cozimento 30s" e "interrompendo o cozimento", todas enquadradas na categoria "como usar" por pelo menos $80 \%$ dos participantes. Para o item "dúvidas mais frequentes" também houve bastante concordância no enquadramento, visto que $90 \%$ dos participantes o inseriram em "guia de soluções".

Para as outras categorias, houve muita dispersão e equívocos de enquadramento, principalmente confundindo partes do microondas com ações que podem ser realizadas. Cumpre ressaltar também a quantidade grande de enquadramentos nas categorias "informações técnicas", "acessórios" e "instalação", possivelmente pelo caráter abrangente dos rótulos.

Nenhum participante enviou comentários, seja pelo próprio websort ou diretamente para o e-mail dos pesquisadores. Portanto, não nos foi possível averiguar a lógica de enquadramento utilizada pelos mesmos ou o nível de dificuldade encontrado na tarefa. Não nos foi possível concluir ainda se a falta de uniformidade dos resultados se deveu à não compreensão da dinâmica e/ou do objetivo do card sorting, ou se os rótulos das informações e/ou categorias geraram dúvidas para os participantes.

Tabela 4 Tabulação dos resultados do card sorting para manual de microondas

\begin{tabular}{|c|c|c|c|c|c|c|c|c|}
\hline \multirow[b]{2}{*}{ cartões } & \multicolumn{8}{|c|}{ \% de inserção nas categorias } \\
\hline & acessórios & $\begin{array}{l}\text { como } \\
\text { usar }\end{array}$ & $\begin{array}{l}\text { partes } \\
\text { do micro }\end{array}$ & $\begin{array}{l}\text { guia de } \\
\text { soluções }\end{array}$ & $\begin{array}{l}\text { inform. } \\
\text { técnicas }\end{array}$ & $\begin{array}{l}\text { instruc. de } \\
\text { segurança }\end{array}$ & $\begin{array}{l}\text { limpeza/ } \\
\text { manuten. }\end{array}$ & instalação \\
\hline posicionamento do forno & & 20 & & & 20 & & & 50 \\
\hline circulação de ar & & & & & 30 & 10 & 40 & 20 \\
\hline circuitos & & & & & 40 & & & 60 \\
\hline disjuntores & & & & & 40 & & & 60 \\
\hline tensão da tomada & & & & & 50 & & & 50 \\
\hline painel de controle & 10 & 20 & 60 & & & & & 10 \\
\hline como o forno funciona & & 80 & & & 10 & & & 10 \\
\hline ajustes de relógio & 40 & 40 & & 10 & & & & 10 \\
\hline $\begin{array}{l}\text { ajustes de tempo de cozimento } \\
\text { e potência }\end{array}$ & & 100 & & & & & & \\
\hline cozimento 30 s & 10 & 80 & 10 & & & & & \\
\hline interrompendo o cozimento & & 90 & & & & 10 & & \\
\hline aviso sonoro & 40 & 40 & & & 10 & & & \\
\hline abrindo a porta do forno & & 50 & 20 & 10 & 10 & & & \\
\hline funções de segurança & 10 & 10 & & & & 80 & & \\
\hline utilizando a trava de segurança & & 10 & & 10 & & 80 & & \\
\hline alterando intensidade luminosa & 30 & 20 & & 10 & 30 & & & 10 \\
\hline dúvidas mais comuns & & & & 90 & & & 10 & \\
\hline
\end{tabular}




\subsection{Card sorting para mapa turístico}

O objetivo de aplicação do card sorting para mapa turístico foi diferente dos apresentados anteriormente (embalagem e manual de instruções). Neste caso, não ocorrem enquadramentos precisos de informações em categorias, pois o mapa apresenta não só relações de pertinência, mas também relações de objeto-atributo ou mesmo relações espaciais e de importância. Portanto, o objetivo do card sorting, desta vez, não foi enquadrar informações, mas estabelecer relações entre as informações apresentadas, para que estas aparecessem, de alguma forma, conectadas no mapa.

Para tanto, inicialmente, extraíram-se as informações do mapa de caráter mais geral, ou que poderiam ser de alguma forma qualificadas ou especificadas: bairros, estações de ônibus, linhas de ônibus, pontos turísticos, praças, ruas, hospitais, orientação (N-S ou L-O). Já as informações especificadoras ou qualificadoras escolhidas foram: principais, secundárias, terminais, ciclovias, trajetos, vias de pedestres, saídas da/acessos à cidade, sentido. A seleção dessas informações se mostrou uma tarefa mais complexa do que a extração de informações da embalagem ou do manual de instruções, necessitando ser conferida por dois pesquisadores externos à equipe antes da montagem do card sorting.

Os participantes, então, relacionaram as informações, podendo acrescentar mais de um qualificador ou informação especificadora para o mesmo item, ou ainda, utilizar o mesmo qualificador para diferentes itens. Por exemplo, o qualificador "principal" poderia se usado tanto para rua principal, quanto para hospital principal, ou ainda para as principais linhas de ônibus. De forma semelhante, uma estação tubo poderia estar em um "terminal" ou uma linha de ônibus poderia levar o passageiro até um "terminal”.

Tabela 5 Tabulação dos resultados do card sorting para mapa turístico

\begin{tabular}{|c|c|c|c|c|c|c|c|c|}
\hline \multirow[b]{2}{*}{$\begin{array}{l}\text { qualificadores/ } \\
\text { especificadores }\end{array}$} & \multicolumn{8}{|c|}{ itens gerais } \\
\hline & bairros & praças & ruas & $\begin{array}{l}\text { pontos } \\
\text { turísticos }\end{array}$ & $\begin{array}{l}\text { estações } \\
\text { de ônibus }\end{array}$ & $\begin{array}{l}\text { linhas de } \\
\text { ônibus }\end{array}$ & hospitais & orientação \\
\hline terminais & & & & & 60 & 40 & & \\
\hline sentido & & & 60 & & & & & 40 \\
\hline \multicolumn{9}{|l|}{ saídas / acessos } \\
\hline da cidade & & & 30 & 10 & 10 & & & 40 \\
\hline ciclovias & 10 & 30 & 40 & 20 & & & & \\
\hline principais & & & 70 & 10 & 10 & & 10 & \\
\hline secundárias & 10 & & 40 & 20 & 10 & 10 & & \\
\hline vias de pedestre & 20 & 20 & 30 & 10 & & & & 20 \\
\hline trajetos & & & 10 & 30 & & 40 & & 20 \\
\hline
\end{tabular}


Os resultados do card sorting para mapa turístico revelaram que o item que mais recebeu qualificadores foi "ruas" (vide tabela 5). Os participantes estabeleceram as relações "sentido das ruas", "ruas de acesso à cidade", "ruas que contém ciclovias", "ruas principais", "ruas secundárias", "ruas de pedestre" e "trajetos envolvendo ruas". Em seguida, aparece o item "pontos turísticos", para o qual os participantes estabeleceram as relações "pontos turísticos nas saídas da cidade", "pontos turísticos acessíveis por ciclovias" ou "que contêm ciclovias", "pontos turísticos principais", "pontos turísticos secundários", "pontos turísticos acessíveis por vias de pedestre" ou "que contêm vias de pedestre" e "trajetos para chegar a pontos turísticos". Os outros itens, apesar de terem recebido menor quantidade de enquadramentos, ainda assim, todas as relações estabelecidas fazem sentido tanto conceitualmente quanto em termos de hierarquia e/ou codificação gráfica a ser utilizada no design do mapa. Isso nos leva a crer que os participantes compreenderam o objetivo da realização deste tipo de card sorting, mesmo sendo tão diferente em termos de propósito da versão original da técnica.

\subsection{Discussão dos resultados da aplicação do card sorting adaptado}

Após a aplicação do card sorting adaptado com três sistemas de informação diferente, foi-nos possível refletir sobre alguns aspectos procedurais. No que se refere aos procedimentos de aplicação do card sorting, cumpre destacar, no que se segue, algumas modificações introduzidas neste estudo e que se mostraram válidas.

A mudança de objetivo do card sorting, em relação à versão original da técnica, ampliou a possibilidade de aplicação dos resultados. Neste estudo, utilizamos o card sorting visando estabelecer relações qualificadoras ou especificadoras entre informações a constar em um mapa turístico. Os resultados permitiram Este é um estágio do design em suporte impresso que geralmente é realizado pela equipe de projeto, sem a participação de usuários, usualmente se servindo de modelos descritivos ou de diretrizes provindas da literatura. A versão adaptada de card sorting possibilitou a participação dos usuários neste estágio.

O uso de material concreto durante a sessão de arranjo de cartões se mostrou bastante útil no caso da embalagem. De posse de uma embalagem planificada que poderia ser montada e desmontada, os usuários tiveram maior facilidade em visualizar onde as informações por eles alocadas seriam colocadas na embalagem, além de ter uma melhor idéia do tamanho de cada face da embalagem, o que também facilita a decisão de enquadramento de informações.

O uso de post-its, ao invés de cartões, também facilitou o arranjo, permitindo que o participante realizasse quantas modificações fossem necessárias até sua decisão final. O material adesivo também facilitou a realização do card sorting na embalagem, ao permitir que a mesma 
fosse manipulada, montada e desmontada, ser que as informações saíssem da posição.

O card sorting adaptado inclui ainda a possibilidade de "clonar" cartões, para que a mesma informação pudesse ser incluída em diferentes grupos. Essa possibilidade não ocorre em sistemas de informação digitais, onde cada informação tem um local determinado e para que seja acessada de outras partes lhe são atribuídos links. No caso de sistemas de informação impressos, como em nosso exemplo de embalagem, as informações precisam ser repetidas nos diferentes grupos.

Por fim, flexibilizamos em nossa versão do card sorting o momento de eliciação. Na versão tradicional da técnica, a eliciação é realizada após o arranjo de cartões. Em nosso estudo, entretanto, verificamos que alguns usuários realizavam comentários durante o processo, como que numa sessão de verbalização espontânea, possivelmente para lhes ajudar a pensar melhor sobre o enquadramento. À semelhança, alguns usuários apresentaram dificuldade para explicar como organizaram as informações quando haviam já concluído a estrutura. Portanto, deixar o momento de eliciação livre, favoreceu a obtenção de informações sobre a lógica de organização dos cartões junto aos usuários.

No que se refere aos resultados da aplicação do card sorting adaptado, foi-nos possível verificar que a técnica é bastante flexível, prestando-se a diferentes sistemas de informação em suporte impresso. Obtiveram-se resultados consistentes tanto para organizar informações em faces de embalagem (enquadramento em categorias pré-definidas, com possibilidade de "clonagem" de informações), quanto para o agrupamento de instruções em capítulos (enquadramento em categorias pré-definidas, sem repetição de informações), ou ainda para gerar atributos para conteúdos informacionais em um mapa (relações de qualificação ou especificação e não de enquadramento). Este último caso foi o mais desafiador, mas ainda assim os usuários conseguiram compreender o objetivo desta forma de aplicação do card sorting.

Os resultados obtidos permitem aplicação direta ao design de sistemas de informação em suporte impresso em diferentes fases do processo de design. Por exemplo, para a embalagem alimentícia, tem-se a arquitetura da informação, sendo possível gerar em seguida malhas de diagramação com as informações enquadradas pelos participantes em cada face. Já para o manual de instruções, tem-se um inventário de conteúdo para cada capítulo, cabendo na sequência trabalhar a ordenação dos mesmos e a diagramação. Por fim, para o mapa turístico, obteve-se o detalhamento de cada um dos itens a compor o escopo do sistema, com a definição das características descritivas de cada um destes (e.g., ruas "principais" e "secundárias", ruas "que possuem" ciclovias), ou seja, que informações complementares o usuário necessitaria para cada um dos itens do 
mapa. Na sequência, pode-se estabelecer níveis hierárquicos de informação e selecionar variáveis gráficas para explicitá-los.

Apesar dos resultados positivos, vislumbram-se ainda algumas necessidades de ajustes para que se obtenha resultados mais úteis e confiáveis:

- deixar claro que o arranjo deve refletir a opinião do usuário e não sua tentativa em lembrar como os sistemas com os quais interage costumam organizar as informações;

- estabelecer a obrigatoriedade de eliciação, para que se possa compreender como e porque o participante organizou as informações de tal maneira;

- disponibilizar comentários sobre o conteúdo por trás de cada rótulo de cartão, ou seja, o que o usuário irá encontrar em cada nó de informação representado pelo rótulo;

- verificar clareza e precisão dos rótulos antes de iniciar arranjo dos cartões, para evitar enquadramentos equivocados por falha na compreensão dos rótulos;

- evitar deixar os cartões embaralhados, dispor de espaço para que o participante abra todos os cartões, compare-os etc, antes de iniciar o arranjo.

\section{Conclusões e desdobramentos}

O presente estudo teve como objetivo adaptar o card sorting para aplicação a sistemas de informação em suporte impresso. Inicialmente, adaptamos conceitos, métricas e procedimentos, para então aplicar a versão adaptada a três sistemas de informação diferentes (embalagem, manual e mapa).

Os resultados demonstraram que os participantes compreenderam os objetivos de aplicação da técnica em sua versão adaptada e que conseguiram organizar coerentemente os cartões fornecidos, de modo a gerar resultados válidos para o design de sistemas de informação em suporte impresso.

Acreditamos que a versão adaptada do card sorting possa contribuir para o desenvolvimento de soluções mais adequadas para os produtos impressos nos níveis de escopo e arquitetura da informação. No que se refere ao escopo, a técnica permite verificar a adequação da rotulagem, e dos itens informacionais propostos, além de definir relações de qualificação e especificação para cada um dos itens. No que tange à arquitetura da informação, é possível definir grupos em diferentes situações e níveis de abstração (e.g., faces de embalagem, capítulos de manuais, camadas de informação em mapas, totens de sinalização - esses dois últimos exemplos ainda não testados). Pode-se ainda utilizar a técnica para avaliar a arquitetura de informação existente, extraindo-se os itens informacionais e solicitando que os usuários os agrupem, para comparar o resultado com a versão original. 
Os resultados obtidos levaram-nos ainda a visualizar algumas possibilidades adicionais à forma como foi conduzido o card sorting neste estudo:

- utilizar o card sorting não apenas para gerar grupos, mas também para ordenar posteriormente os grupos gerados (e.g., gerar capítulos de um manual e então ordenar esses capítulos);

- utilizar o card sorting para gerar hierarquia intra-grupo (e.g., após posicionar as informações nas faces da embalagem, então solicitar que o usuário hierarquize-as).

Como desdobramentos deste estudo, vislumbram-se a produção de um manual com passo-a-passo e dicas sobre como aplicar o card sorting adaptado. Tal manual será disponibilizado a pesquisadores e profissionais da área de Design da Informação. Após a aplicação do card sorting adaptado por pessoas que não estiveram envolvidas no processo de adaptação da técnica (como foi o caso deste estudo), os autores discutirão os resultados com os aplicadores para implementar melhorias na versão atual do card sorting aplicado.

\section{Referências}

CATO, J. (2001). User-centered web design. London: Addison-Wesley.

CYBIS, W.; BETIOL, A. H.; FAUST, R. (2007). Ergonomia e usabilidade: conhecimentos, métodos e aplicações. São Paulo: Novatec Editora.

Hudson, w. (2013). Card Sorting. In: Soegaard, Mads and Dam, Rikke Friis (eds.). The Encyclopedia of Human-Computer Interaction, 2nd Ed. Aarhus, Denmark: The Interaction Design Foundation. Disponível online em: www.interactiondesign.org/encyclopedia/ card_sorting.html. Acesso em: 16.12.2013.

IsO 9241-210. (2010). Ergonomics of human-system interaction - Part 210: Humancentred design for interactive systems.

KUnIAVSKy, M. (2003). Observing the user experience. San Francisco: Morgan Kaufmann.

MAGUIRE. M. (2001). Methods to support human-centred design. Int. J. HumanComputer Studies 55, p. $587-634$.

MAURER, D.; WARFEL, T. (2004). Card sorting: a definitive guide. Disponível online em: http://cuttingedgecourse.com/CIS360/CardSortingGuide.pdf. Acesso em 17.10.2013.

NIELSEN. J. (1993). Usability engineering. San Francisco: Morgan Kaufmann.

PADOVANI. S.; RIBEIRO, M. A.; SCARIOT, C. (2012). Trilhando o caminho de volta: um estudo da adaptação de métodos de design centrado no usuário para sistemas de informação digitais visando aplicação à mídia impressa. In Anais do P\&D Design. São Luiz: UFMA.

Santa Rosa, G.; MORAeS, A. DE. (2012). Design Participativo. Rio de Janeiro: Rio Books.

STICKDORN, M.; SCHNEIDER, J. (2011). This is service design thinking. New Jersey: John Wiley \& Sons. 
WOOD, J. R.; WOOD, L. E. (2008). Card Sorting: Current Practices and Beyond. In Journal of Usability Studies, 4 (1) p. 1-6.

\section{Sobre os autores}

\section{Stephania Padovani}

$<$ s_padovani2@yahoo.co.uk>

Professora e pesquisadora do Programa de Pós graduação em Design da Universidade Federal do Paraná e bolsista de produtividade em pesquisa do CNPq. Atualmente, desenvolve e orienta projetos nas áreas de usabilidade, navegação e interação em dispositivos de interação móvel (e.g, smartphones e tablets), sempre adotando uma abordagem de Design Centrado no Usuário.

\section{Murilo Amgarten Ribeiro}

$<$ muarri@gmail.com>

Graduando em Design na Universidade Federal do Paraná, tendo participado do presente estudo como bolsista de Iniciação Científica. Atualmente, desenvolve seu TCC (Trabalho de Conclusão de Curso) na área de infografia digital, visando contribuir para a prevenção da obesidade infantil.

Artigo recebido em 09 set. 2013, aprovado em 21 dez. 2013. 